\title{
Crítica y tensión: la figura femenina en Los judios de las Acacias
}

Criticism and tension: the female figure in The Jews of the Acacias

\author{
Melina Di Miro \\ melina.deniro@gmail.com \\ Universidad de Buenos Aires \\ Argentina
}

\section{Resumen}

Los judíos de las Acacias (1936), de Rebeca Mactas, presenta siete cuentos ubicados en una colonia agrícola argentina. En un diálogo tácito con Los Gauchos judíos de Gerchunoff, la autora reelabora el proceso de colonización e integración de los inmigrantes, pero ahora desde una perspectiva desencantada y privilegiando las experiencias de las mujeres. Este artículo propone, en primer lugar, analizar la representación de la figura femenina en Los judíos de las Acacias mediante el rol y los rasgos psicológicos de los personajes femeninos en la colonia, y de la mirada sobre ellos de los caracteres masculinos. En segundo lugar, se detallarán las tensiones que la autora implícita en tanto, por una parte, se critican los destinos vitales posibles de la mujer según los regímenes genéricos en el campo argentino y en la tradición judía más conservadora, y por otra parte, se persiste en la naturalización de su destino prescripto en mandatos sociales y religiosos.

Palabras clave: Rebeca Mactas, colonia judía, mujeres, literatura judeoargentina.

\begin{abstract}
Los judios de las Acacias (1936) by Rebeca Mactas presents seven tales located in an agricultural colony in Argentina. In a tacit dialogue with Gerchunoff's Los gauchos judíos, the author re-elaborate the process of colonization and integration of immigrants, but now from a disenchated perspective and puting in the foreground the experiences of women.
\end{abstract}


This article proposes, first of all, to analyze the representation of de female figure in Los judios de las Acacias through the role and the psychological features of the female characters in the colony, and the perspective on them of the masculine characters. Secondly, it will be detailed the tensions of implied author as, on the one hand, the possible vital destinies of women according to generic regimes in the Argentine countryside and in the more conservative Jewish tradition are criticized, and on the other hand, the naturalization of their destiny prescribed in social and religious mandates is mantained.

Keywords: Rebeca Mactas, Jewish colony, Women, jewishargentine literature.

El libro de cuentos Los judíos de las Acacias de la escritora Rebeca Mactas (1914-1997) salió a la luz en el año 1936. Los siete relatos que componen el volumen presentan diversas historias sobre la experiencia de los inmigrantes judíos y sus descendientes en el ámbito de una colonia agrícola en Argentina un vez pasado su periodo de apogeo. Se teje así a través de una narrativa clara y emotiva la lenta agonía del estilo de vida de los pioneros, la fuga de los jóvenes a la ciudad y la soledad de las muchachas que se mustian en el olvido de un pueblo fantasmal: Las Acacias.

Todas las historias ocurren en este poblado y sus alrededores. Se trata de un lugar ficticio que remite, de manera general, a las diferentes colonias fundadas por la Jewish Colonization Asociation (JCA) hacia finales del siglo XIX y principios del siglo XX en el campo argentino. Bajo el espíritu de su creador, el filántropo alemán Baron Moritz von Hirsch, la JCA tenía como fin contribuir al asentamiento de judíos obligados a emigrar de sus lugares de origen por las persecuciones y carencias allí sufridas. ${ }^{1}$ De manera más específica, Las Acacias nos recuerda la Colonia Mauricio en las inmediaciones de Carlos Casares, con su pequeño centro urbano-comercial llamado Algarrobo, el cual con el tiempo

\footnotetext{
${ }^{1}$ A través de la JCA, fundada en 1891, muchos inmigrantes judíos, procedentes en su mayoría de Europa Oriental, lograron organizar su residencia en colonias agrícolas ubicadas principalmente en la provincias de Entre Ríos, Santa Fe y Buenos Aires (cfr. Avni, 2005).

Cuadernos Judaicos ISSN: 0718-8749 
fue quedando tan silencioso como el cementerio que en la realidad y la ficción se hallaba en las cercanías del caserío.

La colonia Mauricio se fundó en 1891 con 567 personas y llegó a contar en 1930 con más de 3000 habitantes. Tras aquel momento de esplendor sufrió un proceso de decadencia que no excluyó la especulación con las tierras. Tan intenso fue el proceso de migración urbana que hacia principios del siglo XXI vivían en Algarrobo solo dos familias... y ninguna era judía (Kapszuk, 2001, pp.46-49). Pero Mauricio ya era parte imborrable de la epopeya mítica de los pioneros. Había vivido en aquella colonia el abuelo de Rebeca, el legendario Marcos Alpersohn, quien en sus crónicas en ídish -Colonia Mauricio: memorias de un colono judío (1922-1928)- narró los pesares y esfuerzos de sus primeros pobladores. La misma Rebeca nació en los alrededores de aquella colonia. Pero tras completar su educación primaria, partió con su familia a Buenos Aires siguiendo la creciente corriente de éxodo hacia la ciudad.

En efecto, luego de los años de auge de la vida agrícola judía hacia 1911-1912, comienza a manifestarse un estancamiento que se agudizaría en la década de 1930 por un proceso multicausal que incluía, entre otras razones, los conflictos con la administración de la JCA, la rígidas condiciones de esta institución para el asentamiento de familias, la atracción y las posibilidades ofrecidas por los centros urbanos, y las crecientes restricciones argentinas a la inmigración (cfr. Theodore Norman, 1985; Avni, 1983).

Cuando Mactas publica su libro habían transcurrido entonces dieciséis años desde que Alberto Gerchunoff (1883-1950) celebrara la colonización de la JCA en un libro fundante de la literatura judeo-argentina, Los Gauchos judíos (1910). Allí el encuentro de los inmigrantes con la pampa cerraba la parábola de la diáspora al concebírselo simbólicamente como la llegada a la Tierra Prometida, donde el estilo bíblico-eglógico de la vida campesina, grata a los ojos de Dios, podría renacer. La obra de Gerchunoff, como ha señalado Hussar (2008), brinda el modelo genérico a Mactas para narrar la colonia. Se trata de un "ciclo de short story" donde relatos de tramas independientes se conectan entre sí a través de la unidad del espacio y la recursividad temática (p.47). 
Sin embargo, la perspectiva narrativa y el tono de la evocación ya no será el mismo. ${ }^{2}$ En primer lugar, el desencanto prima en la reelaboración ficcional que la autora realiza del proceso de colonización. La desolación de Las Acacias, habitada ante todo por viejos pioneros tristes y resignados, hunde sus raíces en el remate de campos por deudas, en la concentración de la tierra en manos de estancieros y en la falta de perspectivas laborales y educativas para los jóvenes. En segundo lugar, en el libro se reordenan como tensiones polos cuyas relaciones no eran mayormente problematizadas en la obra prima de Gerchunoff. Así, los pares campo/ciudad y tradición/asimilación constituyen en Los judíos de las Acacias dos dicotomías ambiguas y yuxtapuestas, pues sus términos componentes condensan tanto rasgos positivos como negativos. La colonia se asocia a los valores de la honradez, el esfuerzo, la cercanía con la naturaleza y un estilo de vida judío-comunitario así como a los rigores del clima y la ausencia de un horizonte de desarrollo económicoprofesional. La ciudad suele ser su contracara, y si allí los personajes tienen lazos con instituciones judías, se recalca ante todo el afán de ostentación y vanidad como motor de su pertenencia a ellas.

En tercer lugar, y es lo que compete a este artículo en particular, mientras en Los gauchos judíos las figuras femeninas constituían mayormente estampas idealizadas de labradoras bíblicas en el contexto entrerriano (Senkman, 1983, pp.23-24), en la obra de Mactas hay una tendencia a configurar críticamente el lugar de la mujer en la colonia, haciendo suyo incluso el punto de vista narrativo. Las ancianas esposas y las jóvenes muchachas son constituidas como personajes portadores de deseos propios que deben lidiar -muchas veces desde el silencio- con situaciones conflictivas. $\mathrm{Y}$ en general se las muestra en su pensar, su sentir y en su compleja posición entre la tradición judía, la nueva vida en el campo argentino y la atracción de la urbe modernizada.

Este artículo se propone, en primera instancia, analizar la representación de la figura femenina en Los judíos de las Acacias a través del rol asignado a las mujeres en el medio

\footnotetext{
${ }^{2}$ En este punto nos separamos del trabajo de Hussar quien ve en Mactas cierta continuidad con el tono celebratorio de la vida campesina en Los gauchos judíos.
} 
sociocultural de la colonia, de la mirada de los caracteres masculinos sobre ellas, y de los rasgos psicológicos atribuidos a los personajes femeninos. En segunda instancia, se detallarán las tensiones presentes en la autora implícita en la medida en que, como se demostrará, por una parte, se articula en la narración una crítica al horizonte de los destinos vitales posibles que le es dado esperar al sujeto femenino según los regímenes genéricos en la colonia agrícola argentina y en la tradición más conservadora del judaísmo rabínico, y por otra parte, se persiste en la naturalización del "destino de mujer" prescripto en el entramado de mandatos sociales y religiosos.

Si bien en los siete relatos del libro se encuentra la presencia de personajes femeninos, serán foco especial del análisis crítico los cuentos La casa y Corazón sencillo. Se trata de dos historias donde la temática y la problemática del lugar de la mujer en la colonia y la familia judía muestran características que las vuelvan paradigmáticas de su representación en la narrativa de Mactas. No obstante, cuando ello sea necesario para iluminar aspectos específicos del análisis, se realizarán referencias al resto de los relatos.

\section{Las judías de la colonia}

En el cuento inicial de Los judíos de Las Acacias se simboliza la crisis de la vida familiar y del bienestar económico en la colonia a través del avatar de la casa del matrimonio de Reb Jaim Kahn y Ana. Se trata de un humilde rancho de adobe, construido por ellos con empeño y honesta labor al llegar a la Argentina. Uno de sus hijos, vuelto un exitoso comerciante en la ciudad, decide remplazarlo contra el deseo de sus padres por un lujoso chalet, al cual ya no los une ningún lazo afectivo y que desencaja con el paisaje natural y con la creciente pobreza de los campesinos. El nuevo chalet representa un progreso económico-material, pero a la vez expone un desarraigo indiferente y cierta decadencia moral. De allí que el padre enferme de tristeza y muera prontamente.

En este relato las decisiones fundamentales que producen transformaciones en la vida familiar se encuentran siempre a cargo de alguno de los personajes masculinos. Las mujeres 
simplemente secundan lo que ellos planean y su accionar se desenvuelve dentro de los límites trazados por sus proyectos. El ejemplo más elocuente se vincula a la experiencia crítica del viaje inmigratorio. Cuando Jaim decide abandonar la Rusia zarista, Ana, poniendo en sordina sus propias dudas, acata obnubilada por la firmeza de su esposo: "la mujer, aunque terriblemente angustiada por la suerte que podrían correr su compañero, su hijito y ella, le siguió callada y dócil, subyugada por aquella voluntad masculina que cual una luz intensísima absorbía todas la de su alrededor" (Mactas, 1936, pp.10-11).

Si el viaje se presenta en la perspectiva de Jaim como un reencuentro sagrado con el trabajo agrícola, su mujer no participa ni en el deseo ni en la decisión del traslado, y además su posición relegada se mantiene intacta en una y otra latitud. Ella se convierte en su "sombra blanca" (p.25). Lo acompaña en la dura domesticación del campo y lo cuida incondicionalmente cuando él enferma, para recibir a cambio el fastidio del marido por su presencia constante. Así, el desplazamiento geográfico no parece incidir sobre la economía genérica anterior al viaje. Pero además, tal ausencia de la decisión femenina sobre la propia vida y la estrechez del horizonte sobre el desarrollo personal se sugiere persistente en la próxima generación. Mientras los tres hijos varones de Ana parten de la colonia para desarrollarse respectivamente como comerciante, doctor, y periodista; su única hija se va del hogar solo porque se casó con un empleado.

Como sostiene Glickman (1994), en Los judios de Las Acacias se pone en escena la perspectiva masculina desde la cual la mujer permanece sin nombre, es "la mujer de". Ella tiene que obedecer al esposo y ser "buena, honesta, trabajadora, corajuda y generosa" (p.302). En efecto, el actuar sumiso y servicial de las campesinas judías en estos relatos se refleja en lo que desde una mentalidad patriarcal los hombres esperan de ellas. De esta forma, la posición socio-familiar de las figuras femeninas es vinculada directamente, con intensión crítica, a una visión conservadora sobre la mujer. Ejemplo de ello es el modo en que Jaim reflexiona sobre su matrimonio: 
Siempre agradecería a Dios haberle llenado de mercedes, y muy especialmente por haberle dado una esposa como Ana, valiente, fuerte, generosa. Aunque la mujer no es más que una mujer, una hembra se podría decir, cuya misión es la de todas las hembras, cuando resulta como la suya una verdadera compañera, apta para compartir la miel y la hiel de la vida, capaz de ordeñar diez vacas, de cocinar para veinte personas, y de labrar la tierra en momentos de necesidad, es una bendición divina (Mactas, 1936, pp.11-12).

No es un hecho casual que semejante reflexión sea insertada en el marco de la plegaria de un judío devoto. Pues en la narrativa de Mactas se pone en tela de juicio tanto el rol que a la mujer le es destinado en el medio socio-cultural de la colonia agraria, como la imagen que de ella se ha sostenido desde el judaísmo rabínico más conservador. En las palabras que componen esta plegaria no se expresa meramente la opinión individual de este personaje sobre su esposa, sino que en ellas resuena también un discurso cultural y religioso sobre la mujer que extiende una de sus raíces a los viejos textos talmúdicos estudiados por Jaim en su juventud (p.7).

Es necesario recordar, siguiendo a Judith Romney Wegner (1998), que en los textos rabínicos clásicos la constitución de la figura femenina se encuentra ya atravesada por normas patriarcales que dominaban y dominarían la cultura judía y sus culturas aledañas por centurias. En la tradición basada en dichos textos la mujer es confinada a la esfera doméstica y al área de las transacciones comerciales privadas, excluyéndola del mundo de las ideas y de los roles de liderazgo (pp.98-99). Y si bien en la Rusia de fines de siglo XIX la preceptiva judía estaba en un proceso de flexibilización -que se incrementaría en la Argentina-, en la representación ficcional de Mactas se denuncia que tal concepción de la mujer seguía teniendo incidencia en la vida de la colonia argentina. 
Así, en el relato Corazón sencillo, el panadero de Las Acacias exhorta a su amigo a no andar con miramientos al pedir la mano de Eva, en los siguientes términos: “- iPonerse a rogar! ¿Qué más quiere ella? ¿Tiene mucha dote? (...) ¡Ir a ponerse de rodillas ante ella! ¿Acaso no eres hombre? (...). Con razón se dice en nuestras oraciones: "Bendito seas, Dios mío, porque no me has hecho mujer" (Mactas, 1936, p.36). El panadero dice esas últimas palabras en hebreo, es decir, en el lenguaje que dentro del bilingüismo (e incluso el trilingüísmo) de las comunidades ashkenazis había sido tradicionalmente patrimonio cultural de los hombres en tanto idioma destinado a la erudición y las prácticas religiosas, esferas estas vedadas a las mujeres (Katz, 2004).

"Gracias Dios por no hacerme mujer" es una de las bendiciones que deben rezar los hombres judíos diariamente, junto al agradecimiento por no ser esclavos, ni gentiles (cfr. Talmud de Babilonia, Menajot, 43b-44). Como explica Shaye Cohen (2005), existe un abultado derrotero de polémicas interpretativas sobre esta frase, pero una de sus versiones canónicas sostiene que se agradece de ese modo pues las mujeres no deben cumplir todas las prescripciones. Es decir, los hombres se consideran bendecidos por poder servir a Dios de múltiples modos. ${ }^{3}$ Ahora bien, una de las explicaciones sobre la causa de tal exoneración reside en que la mujer sería pura intuición y por tanto carecería de la capacidad intelectual para cumplir con toda la preceptiva. ${ }^{4}$ Según Shaye Cohen, allí radicaría también -más allá de que tales restricciones eran funcionales a la mentalidad patriarcal de las culturas aledañas- tanto la razón de que las figuras femeninas en los textos rabínicos clásicos no ocupen cargos de liderazgo ni accedan a las mismas posibilidades educativas, como el hecho de que esto haya sido regla en comunidades judías ortodoxas e incluso conservadoras.

\footnotetext{
${ }^{3}$ La diferencia genérica aquí sería de función y no de esencia, al contrario de otras interpretaciones donde se juzga que la bendición mencionada radica en el supuesto de que la mujer no estaría hecha a imagen de Dios (cfr. Shaye Cohen, 2005).

${ }^{4}$ Existe otra interpretación de la exoneración de la mujer a toda la preceptiva, la cual sostiene que gracias a su intuición ella posee una cercanía más inmediata con lo divino (Cfr. Romney Wegner, 1998) 
En el cuento mencionado, el personaje de Eva -nombre por demás simbólico- es víctima de la visión de la mujer enraizada en esa veta de la tradición judía que manifiestan los hombres que la circundan. Eva vive en el campo con su padre viudo y es pretendida por un campesino de la colonia, llamado Mauricio, a quien ella no ama, pues está enamorada de su primo David, un estudiante de la ciudad. Quebrando la expectativa de la problemática de los matrimonios obligados, aquí el padre de la muchacha, Don Marcos, le permite tomar la decisión sobre su futuro esposo. Sin embargo, no subyace a esta concesión el reconocimiento de la mujer como sujeto libre de voluntad. La autonomía dada a la hija se debe al absoluto desinterés por el devenir de un ser considerado inferior. Para Don Marcos el destino de un hombre es siempre más importante y de mayor razón de orgullo que el de una mujer. Por eso, él, que siempre había anhelado tener un hijo varón que se educara en la sinagoga, decide invertir todo su capital en los estudios universitarios de su sobrino. ${ }^{5}$

Si Eva sufre tal relegamiento en la esfera religiosa y educativa, en el ámbito económico es objetualizada. Como en otros relatos del libro, la mujer es mostrada como una pieza en una economía social regida desde los intereses masculinos. Si ella tiene dote, hay que rogar por su mano -llave de acceso a lo heredado-; si no la posee, se vuelve una mercancía devaluada. De allí que casarse con Eva, "hacerse cargo de ella", es el pago que podría darle David a su tío por el financiamiento de sus estudios; y que el amigo de Mauricio le insista en que no debe rogar por ella... las tierras de su padre están hipotecadas. Por lo demás, como en el cuento La Casa, aquí también la unión matrimonial se asemeja a una transacción para obtener fuerza de trabajo. Si la "honra" de la mujer aumenta su tasación, los campesinos, enfrentados a un medio natural indómito, valoran primordialmente su rendimiento laboral. Incluso para el enamorado Mauricio - o justamente por ello- la cualidad exaltable de Eva es su laboriosidad.

\footnotetext{
${ }^{5}$ Es posible rastrear esta problemática sobre la preferencia de hijos varones en los mismos testimonios de habitantes de las colonias. Así, por ejemplo, Celia Nijamkim refiere: "mi nacimiento fue una gran desilusión para mi padre que esperaba el varón, así fue que no me anotó en el Registro Civil, pero yo existía..." (Gutkowski, 1991, p. 77).
} 
De este modo, las jóvenes de estos cuentos, presas de su condición genérica, se marchitan en la colonia ante la falta de perspectivas de desarrollo personal. De hecho, las posibilidades que se le presentan a Eva para su futuro, su marco de elección, está siempre circunscripto a una figura masculina: o convertirse en esposa de quien no desea, o cuidar al padre viudo, o esperar que el ser amado le proponga matrimonio. Mactas enclava a los personajes femeninos en la colonia mostrando que solo pueden salir de allí a través del casamiento. Ejemplo claro de ello es también el personaje de Clara en el cuento Las Acacias. Esta joven pasa sus días limpiando y cociendo en un pueblo fantasmal donde no hay quien la despose. Pero, a la vez, la autora muestra irónicamente que casarse y cumplir así con lo que es denominado "su destino de hija de Israel" (p.86) puede ser solo un espejismo de liberación.

Incluso más, las pocas mujeres que en este libro son ubicadas en la ciudad -como ocurre con la esposa del exitoso comerciante en La casa, o con Sofía en La vuelta del hijocontinúan dependiendo, económica y emocionalmente, de una figura masculina. Sofía se encuentra subyugada frente a su novio en tanto considera que su realización como sujeto pleno puede darse únicamente mediante su amor. Cuando ella se entera que el muchacho regresará para siempre al campo sin darle ninguna explicación, solo atina a decir: "No hablemos de esa cuestión ¿quieres? Ya sentía yo que nuestro amor era demasiada felicidad para mí. Me elevaba de la eterna humillación femenina. Nosotras las mujeres no estamos acostumbradas a la dicha" (Mactas, 1936, p.108).

Ahora bien, si es cierto que la perspectiva masculina de los personajes de Mactas se compone de elementos provenientes de una ideología patriarcal ligada tanto a una cultura rural conservadora como a la tradición judía mencionada, también lo es -como puede observarse ya en la cita anterior- que la perspectiva de los personajes femeninos no logra constituirse deslindada de sus presupuestos ni en una dialéctica confrontativa con ellos. En el cuento La casa, profundizando formalmente la transformación de la mujer en una "sombra", no hay siquiera espacio narrativo para el fluir de su propia voz íntima. Algo diferente, es verdad, ocurre en el caso de Corazón sencillo. 
En este relato no solo la mayor parte de la historia está enfocada desde el punto de vista de Eva, sino que también hay un trabajo de elaboración de la introspección del personaje femenino. En distintas escenas se muestra al lector el "mundo interior" (p.33) de la muchacha mientras ella realiza tareas del hogar, dando cuenta así de sus pensamientos y sus sentimientos. Pero unos y otros giran siempre en torno a la esfera del amor. No hay prácticamente reflexiones y anhelos de este personaje que no se relacionen con lo que la narradora llama "sus sueños femeninos" (Mactas, 1936, p.34). Ellos son el centro de su intimidad, sea porque se los deja volar, sea porque se los autocensura bajo el parecer de que es necesario sacrificarlos en pos del bienestar de los hombres que la rodean. El "mundo interior" de Eva desconoce la rebelión, la crítica o el enojo consciente ante el lugar que se le otorga en su comunidad.

De esta manera, la cosmovisión machista y sexista que organiza el entramado socio-cultural de la colonia es denunciado únicamente por la autora implícita. Es desde esa instancia que se objetan las injustas jerarquías y la distribución de roles de esta sociedad patriarcal. Esta crítica autoral se instrumenta tácitamente mediante el modo en que se construyen las relaciones intergenéricas en la colonia, la utilización de términos pertenecientes al campo semántico de la dominación para describir vínculos entre hombre y mujeres, y la representación de un discurso sin tapujos sobre la supuesta superioridad masculina en los campesinos. Pero, en contraposición, prácticamente ninguno de los personajes femeninos objeta, ni aun en la soledad, este orden de cosas, ni tensionan desde la proyección imaginaria de sus destinos vitales el horizonte de lo que les es dado hacer y pensar. Eva es incapaz de expresar, incluso en su fuero interno, un atisbo de fastidio y dolor por tener que postrar su vida al pie del padre viudo, o sus anhelos velados de irse del campo. Para ella toda su realidad de relegamiento y sacrificio se ajusta a un natural y necesario "deber ser" (Mactas, 1936, p.46).

Cabe preguntarse si la autora al representar de semejante manera la interioridad de los personajes femeninos recae en la repetición del modelo contra el cual escribe, o si, por el 
contrario, da cuenta así precisamente de cómo ese mandato social es internalizado a tal punto por el sujeto femenino que solo se piensa a sí mismo en función de las figuras masculinas. Los cuentos no ofrecen una respuesta evidente de este interrogante. Por una parte, en el desenlace de Corazón sencillo parecería haber una denuncia de la interiorización del discurso sexista que desplaza al ámbito de lo impensable la autonomía de la mujer. Eva finalmente no puede romper con las cadenas de ese orden social que la conmine a vivir en el ámbito rural al servicio de los hombres y cuando muere su padre, e incluso su primo le propone irse con él a la ciudad, ella decide sacrificarse una vez más casándose con aquel que no ama para cuidarlo en la colonia. Por otra parte, persiste en la perspectiva narrativa y de la autora implícita una concepción genérica que liga los personajes femeninos y el "destino de mujer" exclusivamente a la esfera del amor. Así, por ejemplo, en el poema que preludia Corazón sencillo tiene lugar una estetización de la espera de las campesinas del hombre amado que esteriliza todo potencial crítico; sus "sueños rosados, leves y pequeños" (p. 31) se equiparan con el milagro del florecimiento de un duraznero en una tierra yerma.

Incluso más, el relegamiento de la mujer es vinculado finalmente no a mandatos sociales (externo y/o internalizados) sino al determinismo del medio. En este sentido, recorren el libro diversas imágenes y escenas narrativas donde la naturaleza se presenta o bien como una implacable fuerza telúrica que atrapa a las jóvenes en la colonia, o bien como una madre sabia que enseña a sus criaturas a inmolarse por amor. Es justamente tras escuchar y comprender el mensaje de la voz de la naturaleza que Eva decide quedarse junto al hombre por el que deberá posponer su propio deseo. Y de nuevo el mudo lenguaje de la campiña habla a la muchacha. Pero esta vez la muchacha comprende perfectamente sus palabras: "Se vive únicamente cuando se da", tal es la ley de la tierra. "Obsérvame siempre henchida o germinando; observa las bestias; observa a los pájaros creando sus nidos, ciegos de voluntad; observa a la gallina con su cloqueo, dulce como un canto, mientras su calor hace florecer sus polluelos". “Dar es vivir". "Dar es paz” (Mactas, 1936, p.50). 
Vuelve a hacerse presente así en el libro de Mactas, a pesar de su crítica al rol de la mujer en la colonia, un mensaje conservador y naturalizador de ese mismo lugar puesto en cuestión. Dicho mensaje se articula en la exaltación y la romantización del sacrificio heroico y la idealización del sufrimiento por amor como milagroso acto de entrega. La heroína femenina por excelencia es la madre naturaleza, ella enseña a la mujer a darse en sacrifico en pos de los otros. De allí que se multipliquen las escenas donde se liga fraternalmente a los personajes femeninos con pasivos y generosos animales del campo o con la tierra que aguarda ser germinada. Un ejemplo paradigmático puede leerse en el cuento Fuego. Allí una campesina abraza compasiva a la vaca de la chacra que, tras haber parido, agoniza por una fulminante infección:

Tirada así quejándose tan dolorosamente, no parecía el mismo ser fuerte, dulce y callado, perfecto realizador del sacrificio de la naturaleza. (...). La campesina, que sin darse cuenta aprende siempre de la vaca la fortaleza y el gozo de dar a luz, se arrodilló a su lado y como a una querida hermana infortunada, como a una noble hermana repentinamente enloquecida, la estuvo acariciando largo tiempo. ¡Pobre, pobrecita “Chilena”! (Mactas, 1936, pp. 54-55). ${ }^{6}$

Tal ennoblecimiento del dolor y su asociación a una condición intrínseca de la mujer conduce a que la crítica a la economía genérica en la colonia pierda su potencial develatorio de las relaciones de poder en tanto vuelve a naturalizarse el modo de ser y de existencia de los personajes femeninos. Hay una "voz natural" y un "influjo de la tierra" que pauta, más allá de las motivaciones socioculturales, la conducta de las mujeres en estos relatos. Y esta fuerza del medio físico no tiene el mismo impacto en hombres y mujeres. Al inicio de Corazón sencillo hay una descripción trágica del avasallamiento del clima inclemente sobre

\footnotetext{
${ }^{6}$ Cabe mencionar que, por otra parte, la vaca moribunda es un símbolo múltiple en este relato. Expresa el sacrificio de la mujer-naturaleza, pero también el ocaso de la pujanza económica de la colonia y el desmembramiento de la familia judía entre el campo y la ciudad.
} 
Eva lavando en su batea y sobre los enfardadores de pasto. "Las fuerzas y leyes de a tierra" los esclavizan en esa "brutal tarea" y los atan al medio desolador (p. 33). Sin embargo, si frente a los enfardadores transitan en la narrativa de Mactas distintos personajes masculinos que logran escapar a la ciudad, las mujeres parecen incapaces de derrotar el influjo fatal del medio.

La misma recaída en fundamentos telúricos con relación al accionar de los caracteres femeninos así como la concepción de que la consecución de la felicidad depende del amor de y a un hombre reaparecen incluso en un relato como Primaveras donde la protagonista es, en principio, una figura disruptiva respecto a las convenciones sociales patriarcales. Miriam, la hija del empobrecido carrero de la colonia, es una muchacha curiosa e inteligente. La joven sobresale en la escuela y los cursos de hebreo de tal forma que llega a ser la discípula dilecta del maestro Rabí Naftalí, quien juzga que solo ella es capaz en la colonia de comprender intrincados pasajes de los Salmos. Como el corderito escapado de la manada pasiva destinada al matadero, que la muchacha encuentra en sus paseos campestres, Miriam también huye del corset de los bailes sociales donde se exponen las campesinas y de la monotonía de las tareas domésticas: "un imperioso deseo de moverse, de correr, de saltar, la impulsaba afuera"(Mactas, 1936, p.128).

Sin embargo, la inmensa angustia de la soledad fantasmal de su cuarto únicamente encuentra alivio al conocer a Juan, un muchacho comunista que regresa a la vida rural tras la falta de trabajo en la ciudad. Tal es la felicidad a su lado que el pronombre personal en tercera persona para referirse al joven se encuentra escrito siempre con mayúscula - "Él"- a la manera de Dios. Pero el amor de Miriam nace bajo un signo fatal, pues según se explica en el relato, ella es uno de los seres en los cuales la Primavera ejerce una influencia fatídica. La muchacha está sujeta a su fluido trágico: "hasta el camino de la muerte le hubiera parecido natural, si la voz de la naturaleza se lo hubiera ordenado" (Mactas, 1936, p.124). Y dramático será el desenlace de este amor. El joven comunista debe partir nuevamente a la ciudad, pues nadie quiere emplearlo, y ella queda, en un sacrificio esperanzado, aguardando en el pobre rancho la vuelta del ser amado. 


\section{Transgresoras en la colonia}

La literatura sobre las colonias judías se ha valorado frecuentemente por conservar la memoria de las penurias y proezas de aquel complejo encuentro con un nuevo medio físico y cultural. Ponderando su valor documental -exaltado incluso a veces por sus propios autores (ver, por ejemplo, Tierra soñada (1959) de José Lieberman) - no ha estado exenta de su utilización como fuente para investigaciones históricas. En la escritura de Rebeca Mactas hay una evidente intención estética que impediría cualquier reduccionismo de sus relatos a una mimesis mecánica de la vida en el medio rural. No obstante ello, es pertinente preguntarse en qué medida su obra da cuenta de la realidad histórico-social de las inmigrantes judías y sus hijas en el campo argentino.

En este sentido, la estreches del horizonte de desarrollo personal y profesional para los personajes femeninos en Los judíos de las Acacias hace justicia a lo que padecieron muchas mujeres en las colonias agrícolas. Marginadas para los puestos de liderazgo, la educación y la construcción de trayectorias individuales fuera del hogar, las mujeres eran a la vez requeridas para las duras labores del campo. En este sentido, señala Myriam Escliar:

Aunque la mujer era menospreciada, debía realizar las mismas tareas que el hombre y todas las otras que la concepción machista de la sociedad las obligaba a hacer. Montaba a caballo, muchas veces en pelo, y así al galope cruzaba el campo para llevarle a su marido, a su hijo, a su hermano o a algún peón que los ayudaba, la comida del mediodía; recogía los huevos y acarreaba agua para llenar la batea (...). (1996, p. 36).

Sin embargo, es importante observar que el conjunto de relatos que compone el libro de Mactas no constituye una fotografía exacta de las múltiples experiencias históricas de las 
inmigrantes judías y sus hijas. Según los estudios de Sandra Mcgee Deutsch (1997, 2010), el lugar socioeconómico y cultural de las mujeres judías en el campo argentino no fue homogéneo. Como explica la autora, aunque ellas vivieron allí aún dentro de una cultura patriarcal, semejante a la de la sociedad mayoritaria que integraban, las inmigradas de Europa del Este tuvieron más oportunidades educativas y de desarrollo comunitario en las colonias que lo que habían tenido en sus lugares de origen. En términos generales, las mujeres se ocupaban de la vida doméstica, pero también de actividades centrales para mantener la comunidad de pertenencia a la vez que se trazaban puentes con el nuevo país. Así, solían encargarse de la preparación de comidas diarias y de las festividades, pero también se desempeñaron como maestras y organizaron bibliotecas. Asimismo, subraya Mcgee Deutsch que si por una parte hacia 1914 solo el $48 \%$ de las judías rusas sabían leer y escribir -debido a la pobreza, a la dificultad para ir a la secundaria una vez terminada la escuela primaria de la JCA, y también al desinterés inicial de los padres por la educación religiosa para sus hijas brindada en esas escuelas-; por otra parte, con el tiempo, muchas madres quisieron que sus muchachas estudiaran. Y si lo más común entonces fue que se dedicaran a las "actividades femeninas consideradas legítimas", como bordado y música, muchas llegaron a ser maestras, incluso de hebreo, cruzando la barrera tradicional de la cultura ancestral que mantenía a las mujeres lejos de la enseñanza, y también parteras (Mcgee Deutsch, 2010, cap. 1).

Mactas también presenta algunas "rebeldes" en la colonia. Pero lejos de emerger entonces narrativas que desarrollan la autoafirmación de trayectorias femeninas que logran imponerse a las limitaciones de su ambiente, suelen ser, aunque significativas, apariciones fugaces. La rebeldía de estos personajes es ante todo un medio para subrayar los prejuicios y preconcepciones sobre el "destino de mujer" contra el que deben erigirse. ${ }^{7}$ De allí que sea en la representación literaria de un discurso patriarcal vinculado tanto a la cultura rural

\footnotetext{
${ }^{7}$ Cabe observar cómo también en una serie de obras del teatro ídish en la Argentina a principios de siglo XX la representación de los personajes femeninos gira en torno a su actitud (sea de acatamiento, incumplimiento o abierto desafío) frente al modelo canónico familiar y comunitario, basado en el casamiento endogámico y la maternidad (Cfr. Skura y Hansman, 2006). 
como a la tradición judía conservadora donde deba verse uno de los nexos primordiales de Los judios de las Acacias con su coyuntura histórico-social.

No casualmente las "rebeldes" de Mactas, aquellas mujeres que defienden su propio parecer o trazan un camino disruptivo, sostienen siempre una relación tensionada con las costumbres judías. Así, en el cuento Los judíos de Las Acacias es Sara Ravinoy, contra el deseo de su esposo, quien decide liberar a sus hijos de la pobreza en que se hundió la familia al perder sus campos y enviarlos a la ciudad. Ella antepone al resguardo de la tradición la preocupación por el bienestar económico de su progenie:

Si antes había vivido comprimida por la cómoda vida hogareña, después lo fue por el temor, en compañía de un hombre egoísta y dominante. Empero toda su fuerza y su temperamento estallaron con la maternidad. (...). Aunque con un dolor intenso, hizo que los muchachos abandonaran el hogar para estudiar en las grandes ciudades, pese a que sabía y Moisés no dejaba de repetírselo, que olvidarían las fórmulas del judaísmo, en un medio pagano. (Mactas, 1936, p. 90).

Dos ejemplos más de comportamientos transgresores se encuentran respectivamente en el personaje de Fanny, la madre de Miriam en Primaveras, y la nieta del viejo Menasché en Los judios de las Acacias. En ambos casos apenas son mencionados los actos disruptivos que ellas cometen. Sin embargo, la fuerza de sus decisiones se manifiesta a través de las reacciones que provocan sus actos. De Fanny se dice que paga caro "el instante de su juventud en que sintió la necesidad de ir bailando por su senda en vez de caminar con los ojos bajos" (p.125). Más allá de sugerirse así que su falta fue unirse libremente al hombre que amaba, nunca se aclara qué fue lo que hizo exactamente, aunque sí su consecuencia: la maledicencia de toda la comunidad sobre ella y su apartamiento en la sinagoga incluso durante "los días terribles" (Mactas, 1936, p.125). 
El segundo caso versa sobre un matrimonio mixto, uno de los tópicos por excelencia en la literatura judeoargentina para simbolizar acercamientos y tensiones en los procesos de integración interculturales. Este tópico es aquí tramitado en unas breves líneas que condensan la conmoción causada por la fuga del personaje a su rol de "hija de Israel": "Una nieta se casó con un cristiano. Entonces el anciano, abrumado y asombrado ante la fuerza de su Destino, cerró sus puertas al mundo considerándolo algo impuro y pequeño" (Mactas, 1936, p.93).

En las actitudes reaccionarias y defensivas que generan las "rebeldes" de la colonia se traslucen una vez más los regímenes genéricos que organizan el mundo de las Acacias. Y además se pone al descubierto su asociación no solo con la perpetración de una cultura rural conservadora sino también con el resguardo de una sociabilidad judía tradicional. El enojo del marido de Sara, el apartamiento en la sinagoga de Fanny, y el atrincheramiento del viejo Menasché dan cuenta de la resistencia de la comunidad al cambio de costumbres y de la fuerza virtual para la transformación que se vislumbra en la mujer.

\section{Reflexiones finales}

Los judíos de las Acacias fue un libro que pasó prácticamente desapercibido por parte de la crítica al momento de su aparición. Esa situación no cambiaría tampoco en las décadas subsiguientes y, de hecho, el libro no gozó de una segunda edición. El lugar destacado que Alberto Gerchunoff tuvo en la literatura sobre las colonias y el hecho de que Los gauchos judíos se reeditara justamente el mismo año en que se publicó la obra de Mactas pudieron haber contribuido a su relegamiento. Pero quizá también deba buscarse otra respuesta posible al eclipse de su narrativa en las mismas normas patriarcales que parecía regir entonces el campo literario en la Argentina, más allá de la particularización de ciertas figuras femeninas destacadas -piénsese por ejemplo en Victoria Ocampo o en Alfonsina Storni. 
Podría decirse que la propia Rebeca Mactas fue en cierta forma una transgresora. Su trayectoria biográfica no se plegó al "destino de una hija de Israel” ni al lugar convencional reservado mayoritariamente para las mujeres en la colonia. Quebrando la asociación entre la figura femenina y el ámbito exclusivo del hogar, Mactas deviene escritora. Y no solo escritora de ficción, ella fue además periodista. Se desempeñó como secretaria de redacción del periódico ídish Morgen Zaitung (El matutino) y como traductora. Llevó al español desde el hebreo poemas de J.N Bialik y de Yehuda Halevi, y tradujo del ídish textos de Sholem Asch y de José Rabinovich (cfr. Weinstein y Gover de Natsatky, 1994.; Lockhart, 1997).

Asimismo, como sucede con las escasas "rebeldes" de Las Acacias, en Mactas también parece haber existido una relación compleja con el judaísmo y la judeidad. Rebeca no llevaba una vida religiosa. Su marido, Carlos Polak, era ateo, y su familia no iba a la sinagoga, ni observaba el Día del Perdón, Rosh Hashanah o Pésaj. ${ }^{8}$ Sin embargo, como señala Hussar, es evidente por la temática de su escritura y las figuras abarcadas en sus traducciones y ensayos que ella sintió un lazo inescindible con el universo cultural de su comunidad de origen. Los nombres de algunos de sus ensayos iluminan ese vínculo intenso: El amor a través de los poetas judíos (1933) y Tres expresiones de la poesía de Israel (1969). Títulos a los que puede agregarse el de su libro Leyendas y parábolas judías según la Agadá (1950).

Al observar la trayectoria biográfico-profesional de Mactas se comprende el modo en que su lugar de enunciación se constituye como un particular espacio de frontera. Su escritura se afirma entre el adentro y el afuera de la colonia agraria, entre su subjetividad femenina y su cuestionamiento de las convenciones genéricas, entre su pertenencia judía y su distanciamiento de la judeidad. Desde ese lugar liminar pudo escribir en 1930 un libro como Los judíos de las Acacias donde, a pesar de las limitaciones mencionadas, se plantea una crítica al horizonte de los destinos vitales que le es dado esperar al sujeto femenino

\footnotetext{
${ }^{8}$ Estos datos son provistos por el hijo de Rebeca Mactas a James Hussar, cfr. Hussar, 2008, p. 166. 
según los regímenes genéricos en el campo argentino y en la tradición judía más conservadora.

En efecto, aunque en sus relatos se encuentran índices de una persistencia de la naturalización del "destino de mujer" prescripto en el entramado de mandatos sociales y religiosos, es innegable el aporte de Rebeca Mactas a la literatura judeoargentina. Ella crea un lugar allí para una perspectiva narrativa que elaborara la experiencia de la inmigración y la integración al nuevo país desde las problemáticas de las mujeres. Pero además, como intentamos demostrar aquí, logra hacer imprescindible su nombre de escritora en un ámbito donde la norma era la multiplicación de plumas masculinas. Dejar en las sombras la obra de Mactas implica un cercenamiento de las experiencias judías en el campo argentino y de una creación literaria cuyo valor, por su tenor crítico y su elaboración estética, excede lo documental. 


\section{Bibliografía}

Avni, H. (1983). Argentina y la historia de la inmigración judía 1810-1950. Buenos Aires: Magnes.

Cohen, S. (2005). Why Aren't Jewish Women Circumsiced? Gender and Covenant in Judaism. Berkely: University of California Press.

Escliar, M. (1996). Mujeres. En la literatura y la vida judeoargentina. Buenos Aires: Milá.

Glickman, N. (1994). "Jewish Women Writers in Latin America”. En J. R. Baskin (ed.) Women of the World: Jewish Women and Jewish Writing (pp.299-322). Detroit: Wayne State University Press.

Gutkowski, H. (1991). Vidas...en las colonias: rescate de la herencia cultual en las colonias. Buenos Aires: Contexto.

Hussar, James (2008): Cycling through the Pampas: Fictionalized Accunts of Jewish Agricultural Colonization in Argentina and Brazil. University of Notre Dame: UMI.

Kapszuk, E. (2001). Shalom Argentina: huellas de la colonización judía. Tracing jewish settlement. Buenos Aires: Ministerio de Turismo, Cultura y Deporte.

Katz, D. (2004). Words on fire. The Unfinished Story of Yiddish. Nueva York: Basic Books. 
Lockhart, D. (1997). "Mactas, Rebeca”. En Jewish Writers of Latin America: A Dictionary (pp. 358-362). New York: Routledge.

Mactas, R. (1936). Los judios de Las Acacias (cuentos de la vida campesina). Buenos Aires: Julio Glassman.

McGee Deutsch, S. (1997) "Women: the Forgotten Half of Argentine Jewish History". Shofar Vol. 15, N. 3, 49-65.

McGee Deutsch, S. (2010). Crossing Borders, Claiming a Nation: A History of Argentine Jewish Women 1880-1995. Durham: Duke University Press.

Norman, T. (1985). An Outstretched Arm: A History of the Jewish Colonization Association. London: Routledge and K. Paul.

Romney Wegner, J. (1998). "La imagen y el estatus de la mujer en el judaísmo rabínico clásico". En J. R. Baskin (ed.), Jewish Women in Historical Perspective (pp.73-100). Detroit, Wayne State University Press.

Senkman, L. (1983). La identidad judía en la literatura argentina. Buenos Aires: Editorial Pardes.

Skura, S. y Hansman, S. (2006). "Novias, princesas y farsantes. Personajes femeninos en los comienzos del teatro ídish en Argentina”. En P. Sneh (coord.), Buenos Aires ídish (pp.145-152). Buenos Aires: Gobierno de la Ciudad de Buenos Aires.

Weinstein, A. y Gover de Natsatky, M. (1994). Escritores judeo-argentinos. Bibliografía 1900-1987. Tomo II, (pp.5-7). Buenos Aires: Milá. 